\title{
Snow Melting by Heating from the Bottom Surface*
}

\author{
Kazuo AOKI**, Masaru HATTORI** \\ and Takashi UJIIE***
}

\begin{abstract}
The melting process of a snow layer has been investigated for the case where heat is supplied from the bottom and the meltwater drains continuously. The melting was divided into three patterns, depending on the existence of an ice lens formed by the refreezing of permeating water. A one-dimensional melting model including the draining of meltwater was formulated to account for water permeation and its refreezing in a snow layer. The calculated results for the time variation of each layer and the rate of water drainage are in agreement with the experimental results obtained using compacted and granulated snow. It is found that the melting time and the melting efficiency are affected by water permeation and its refreezing, and the results calculated assuming the classical Stefan problem by neglecting water permeation predict a higher melting efficiency.
\end{abstract}

Key Words: Phase Change, Thermal Conduction, Snow Melting, Porous Layer, Water Permeation, Capillary Action

\section{Introduction}

The melting of snow is an important problem related to the optimum systems and conditions for snow removal in various countries. Usually, snow melting is treated as a conduction problem with phase change, but it cannot be easily considered as the melting of a uniform layer such as ice. The melting of porous materials such as snow is characterized by the permeation of melted water due to capillary action or gravity. In addition, when the temperature in a snow layer is lower than the fusion temperature, refreezing of the permeating water occurs in the layer.

For snow layer of smaller thickness than the height of the water level controlled by capillary action, we have investigated the melting of snow in both cases where heat loss from the top of the body

* Received 21st September, 1987, Paper No. 86-1322 A

** Department of Mechanical Engineering, Technological University of Nagaoka, 1603-1 Kamitomioka, Nagaoka, 940-21, Japan

*** Fuji Electric Co., Ltd., 1-21-1 Yuraku-cho, Chiyodaku, Tokyo, 100, Japan does not exist [1] and where it exists [2] during the melting process, and have developed an analysis of the melting problem considering water permeation and its refreezing.

The extent of water rise by capillary action has a limit related to the structure of porous materials. When the snow layer is sufficiently thick in comparison with the height of the water level controlled by capillary action, it may be observed that an ice lens due to refreezing of the permeating water is formed inside the body. In this paper, in order to apply to the actual process of melting snow, our model has been extended for the case where the thickness is sufficiently high and the meltwater drains from the bottom.

\section{Nomenclature}

$a:$ thermal diffusivity, $\mathrm{m}^{2} / \mathrm{s}$.

$d:$ grain diameter, $\mathrm{mm}$.

$E$ : body thickness, $\mathrm{cm}$.

$E_{0}$ : initial snow thickness, $\mathrm{cm}$.

$h$ : heat transfer coefficient, $\mathrm{W} / \mathrm{m}^{2} \mathrm{~K}$.

$I:$ resistance against water permeation due to refreezing. 
$L:$ latent heat of fusion, $\mathrm{kJ} / \mathrm{kg}$.

$m$ : water permeation rate, $\mathrm{kg} / \mathrm{m}^{2} \mathrm{~h}$.

$P^{+}$: dimensionless capillary suction pressure, defined by Eq. ( 3 ).

$q$ : heat flux, $\mathrm{W} / \mathrm{m}^{2}$.

$q_{0}:$ supplied heat flux, $\mathrm{W} / \mathrm{m}^{2}$.

$S$ : water content ratio.

$S_{c}$ : limiting water content ratio.

$T$ : temperature, ${ }^{\circ} \mathrm{C}$.

$u_{x}$ : velocity due to the reduction in volume, $\mathrm{m} / \mathrm{h}$.

$W:$ water drainage rate, $\mathrm{kg} / \mathrm{m}^{2} \mathrm{~h}$.

$x_{1}$ : position of the water permeation front, $\mathrm{m}$.

$x_{2}$ : position of the ice layer front, $\mathrm{m}$.

$\alpha$ : reciprocal of tortuosity.

$\varepsilon$ : porosity.

$\eta$ : melting efficiency.

$\theta:$ time, $\min$.

$\lambda:$ thermal conductivity, $\mathrm{W} / \mathrm{mK}$.

$\mu$ : viscosity, $\mathrm{Pa} \cdot \mathrm{s}$.

$\rho:$ density, $\mathrm{kg} / \mathrm{m}^{3}$.

$\sigma:$ surface tension, $\mathrm{N} / \mathrm{m}$.

$\phi_{i c e}:$ volume fraction of ice resulting from refreez ing.

\section{Subscripts}

$E:$ top surface of the body.

$i$ : ice layer.

$p:$ porous layer.

$w:$ water.

$w p:$ water permeation layer.

$O$ : initial state.

$\infty$ : ambient surroundings.

\section{Melting Process of a Snow Layer}

We will discuss the melting of snow for the case where heat is supplied from the bottom of the snow layer. Water drainage also occurs at the bottom and there is heat loss from the top of the body to the surroundings with a constant heat-transfer coefficient. The melting can be divided into three patterns, depending on the existence of an ice lens formed by the refreezing of the permeating water. The three pat terns, $\mathrm{A}, \mathrm{B}$ and $\mathrm{C}$, are explained below by referring to a schematic diagram shown in Fig. 1.

Pattern A occurs in the case where the temperature in a snow layer is held uniformly at $0^{\circ} \mathrm{C}$. An ice lens due to the refreezing of the permeating water is never formed. The melting process is briefly explained as follows. When heat is supplied from the bottom, melting takes place. The resulting water rapidly permeates into the porous layer by capillary action and forms a water permeation layer. As melting progresses, the water content in the water permeation layer and thus, the thickness of the layer increase. When the bottom part of the layer is saturated with meltwater and the melting rate on the melting surface exceeds the permeation rate of water away from the surface, part of this water begins to drain from the bottom side. The difference between patterns A 1 and A 2 is whether water drainage occurs before the water permeation front reaches the top surface of the body or after.

Pattern B occurs in the case where a snow layer is subcooled, that is, heat loss from the top surface to the surroundings exists during melting, and is characterized by the formation of an ice lens at the top of the layer. When a snow layer is subcooled, part of the permeating water always refreezes on the water permeation front and the refreezing may act as a resistance against further water permeation. In this pattern, as long as the water permeation front exists inside the body, the permeating rate of water on the front is larger than the refreezing rate. An ice lens is never formed inside the body, but is formed at the top of the body where water permeation stops. The melting process is completed after the melting of the water permeation layer and the ice layer. The difference between patterns B 1 and B 2 is the same as described above.

Pattern $\mathrm{C}$ is characterized by the formation of an

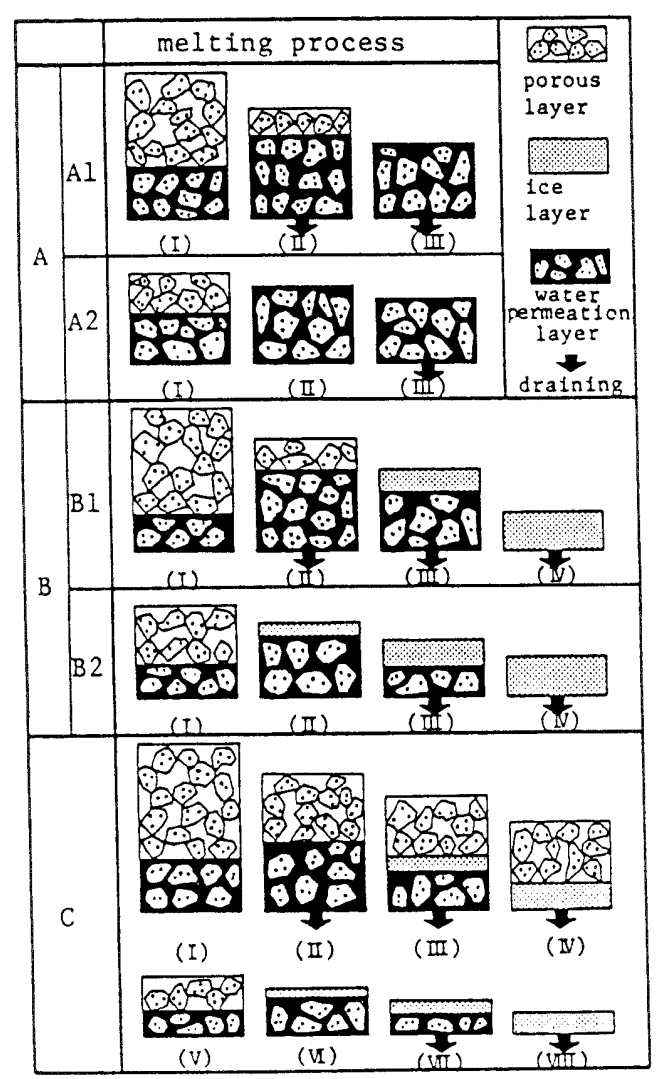

Fig. 1 Classification of melting patterns 
ice lens inside the body. Namely, when the water permeation front is inside the body, the permeating rate on the front becomes smaller than the refreezing rate, and an ice lens begins to form beneath a porous layer. Following the melting of the water permeation layer and the ice layer, the remaining porous layer begins to melt. Accordingly, the process of the melting of the porous layer, the water permeation layer and the ice layer is cyclic in nature.

Melting patterns depend on the initial snow layer thickness, the snow particle diameter, the supplied heat flux, the heat-transfer coefficient, and the ambient temperature. Based on the observations, Figure 2 indicates an example of the classification of the melting patterns under the fixed conditions of snow particle diameter, supplied heat flux, and heat-transfer coefficient. Melting pattern A occurs in the case of the ambient temperature at $0^{\circ} \mathrm{C}$. In subcooled snow layers, it is found that the maximum thickness of the initial snow layer, taking melting pattern $B$, decreases with lower ambient temperature. The maximum value may also depend on the snow diameter, the supplied heat flux and the heat-transfer coefficient, and will decrease further with a larger snow particle diameter, supplied heat flux, or heat-transfer coefficient.

\section{Analysis}

\section{1 Melting model}

Figure 3 shows a typical model for melting pattern $\mathrm{C}$. The model includes the water permeation layer, the ice layer, the porous layer and the water draining from the bottom. A temperature gradient exists in the ice layer and the porous layer. In the water permeation layer, a water content gradient exists, and the temperature distribution is uniform at $0^{\circ} \mathrm{C}$. The model presented here is the modified version of the previous one [2]. The refreezing of permeating water on the water permeation front causes an increase in the resistance against water permeation.

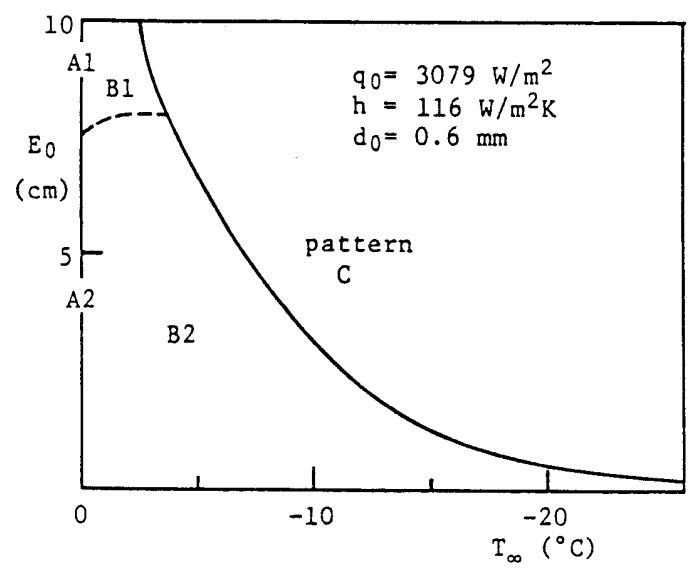

Fig. 2 Typical distributions of melting region
In the previous work [2], this effect was considered to be an increase in particle diameter, based on the assumption of a uniform structure over the water permeation layer. For a thicker snow layer as compared with the extent of water rise, however, it is difficult to explain the increase in the resistance only in terms of an increase in particle diameter. Here, we introduce the following empirical relation, obtained by Taylor et al.[3] through experiments on water permeation in frozen soil as a resistance to water permeation :

$$
I=10^{10 . \phi_{i c e}}
$$

where $\phi_{\text {ice }}$ represents the volume fraction of ice that resulted by refreezing. Also, the change in density due to refreezing is assumed as follows. In periods when the water permeation layer extends into the porous layer, the change is considered under the assumption that the structure is always uniform over the water permeation layer. In periods when an ice lens is formed, the change is regarded only as the formation of an ice layer.

The water drainage occurs when the melting rate on the melting surface is greater than the permeation rate away from the surface. It is further assumed that the melting is one-dimensional and that the density of ice is equal to that of water.

\section{2 Analysis of the melting process}

The water permeation rate in porous materials under unsaturated conditions is very complicated, because the rate depends on the structure of the porous materials and the water content associated with capillary force and gravity. Here, the following empirical correlation, which was derived by Otani and Maeda [4] using the gradient of capillary suction pressure as a driving force in Krischer's model, is employed [5] [6].

$$
m=-\frac{\varepsilon^{2}}{12(1-\varepsilon)} \frac{\sigma d}{\mu} \bar{\rho}_{w} \bar{\alpha}\left\{\frac{\varepsilon}{6(1-\varepsilon)} \frac{\rho_{w} d}{\sigma}-\frac{\partial P^{+}}{\partial x}\right\}
$$

where

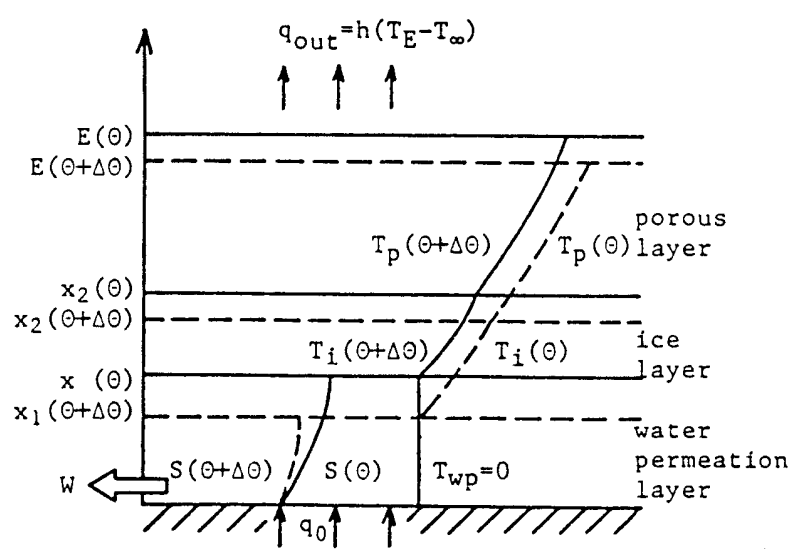

Fig. 3 Typical melting model in melting pattern $\mathrm{C}$ 


$$
\begin{aligned}
& P^{+}(S)=\frac{P}{\sigma} \frac{\varepsilon}{(1-\varepsilon)} \frac{d}{6}=1.6 \exp (-0.46 \mathrm{~S}) \\
& -\exp \{20(\mathrm{~S}-1)\} \\
& \bar{\alpha}(S)=\alpha \int_{S_{c}}^{S} \frac{1}{\left(P^{+}\right)^{2}} d S=0.67 \exp \{6(S-1)\}
\end{aligned}
$$

For increases in the resistance against water permeation due to refreezing, the rate is represented by dividing Eq. (2) by Eq. (1).

Next, we explain a typical analysis of the melting process for period (III) in pattern $\mathrm{C}$, which is composed of the water permeation layer, the ice layer and the porous layer. The governing equations for each layer are

$$
\begin{aligned}
& T_{w p}=0, \varepsilon \rho_{w} \frac{\partial S_{w p}}{\partial \theta}=-\frac{\partial m}{\partial x}-u_{x} \varepsilon \rho_{w} \frac{\partial S_{w p}}{\partial x} \\
& \frac{\partial T_{i}}{\partial \theta}=a_{i} \frac{\partial^{2} T_{i}}{\partial x^{2}}-u_{x} \frac{\partial T_{i}}{\partial x} \\
& \frac{\partial T_{p}}{\partial \theta}=a_{p} \frac{\partial^{2} T_{p}}{\partial x^{2}}-u_{x} \frac{\partial T_{p}}{\partial x}
\end{aligned}
$$

The velocity, $u_{x}$, which occurs due to the reduction in body volume, can be written in this period as

$$
u_{x}=-\frac{q_{0}}{L \rho_{p}}
$$

\begin{tabular}{|c|c|}
\hline period & boundary conditions \\
\hline (I) & $\begin{array}{l}x=0 ; q=q_{0},(m)_{x=0}=\frac{g \rho_{0}}{L \rho_{p}}\left(\rho_{p}+\varepsilon \rho_{w}(S)_{x=0}\right) \\
x=x_{1} ; \frac{S=S c, T_{1}=0}{d \theta} \frac{1}{\varepsilon \rho_{w} S c}(m)_{x=x_{1}} \frac{1}{\varepsilon \rho_{w} S c} \frac{\lambda_{p}}{L \rho_{p}}\left(\frac{\partial T_{p}}{\partial x}\right)_{x=x_{1}}+u_{x} \\
x=E ; \frac{d E}{d \theta}=u_{x}, q=h\left(T_{E}-T_{\infty}\right)\end{array}$ \\
\hline (II) & 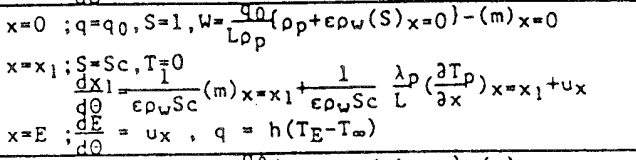 \\
\hline (III) & 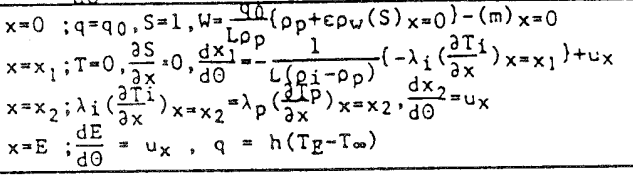 \\
\hline$(\mathbb{N})$ & 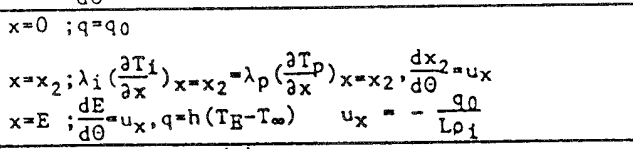 \\
\hline (V) & period (I) \\
\hline (U) & 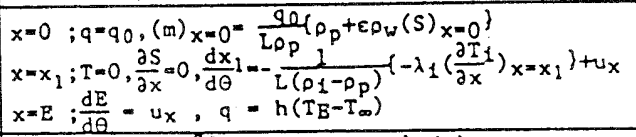 \\
\hline (VII) & $\begin{array}{l}x=0 ; q=q 0, h=\frac{q g}{L \rho_{p}}\left(\rho_{p}+\varepsilon \rho_{w_{w}}(S) x=0\right\}-(m) x=0 \\
x=x_{1} ; T=0, \frac{\partial S}{\partial x}=0, \frac{d x}{d \theta}=-\frac{1}{L\left(\rho_{1}-\rho_{p}\right)}\left(-\lambda_{1}\left(\frac{\partial T}{\partial x}\right)_{x=x l}\right)+u_{x} \\
x=E ; \frac{d E}{d \theta}=u_{x}, q=h\left(T_{E^{-}}-T_{\infty}\right)\end{array}$ \\
\hline (III) & $\begin{array}{l}x=0 ; q=q 0 \\
x=E ; \frac{d E}{d \theta}=u_{x}, q=q\left(T_{E}-T_{\infty}\right) u_{x}=-\frac{q \rho}{L \rho_{i}}\end{array}$ \\
\hline
\end{tabular}

The boundary conditions at the heating surface, the water permeation front, the ice layer front, and the free end of the body are

Table 1 Boundary conditions for each period in melting pattern $\mathrm{C}$

$$
\begin{aligned}
& x=0 ; q=q_{0}, S=1, \\
& W=\frac{q_{0}}{L \rho_{p}}\left\{\rho_{p}+\varepsilon \rho_{w}(S)_{x=0}\right\} \\
& x=x_{1} ; T=0, \frac{\partial S}{\partial x}=0 \\
& x=x_{2} ; \lambda_{i}\left(\frac{\partial T_{i}}{\partial x}\right)==\lambda_{p}\left(\frac{\partial T_{p}}{\partial x}\right) \\
& x=E ; q=h\left(T_{E}-T_{\infty}\right)
\end{aligned}
$$

where $W$ represents the rate of water drainage. Also, the moving velocity of the water permeation front is represented as

$$
\frac{d x_{1}}{d \theta}=-\frac{1}{L\left(\rho_{i}-\rho_{p}\right)}\left\{-\lambda_{i}\left(\frac{\partial T_{i}}{\partial x}\right)_{x=x_{1}}\right\}+u_{x}
$$

where the first and second terms on the right-hand side represent the reduction velocity of the water permeation layer due to the growth of the ice layer and the melting of the water permeation layer, respectively.

On the other hand, in periods (I),(II) and (V) when the water permeation layer extends into the porous layer, the moving velocity of the water permeation front is represented as

$$
\frac{d x_{1}}{d \theta}=\frac{1}{\varepsilon \rho_{w} S_{c}}(m)_{x=x_{1}}+\frac{1}{\varepsilon \rho_{w} S_{c}} \frac{\lambda_{p}}{L \rho_{p}}\left(\frac{\partial T_{p}}{\partial x}\right)_{x=x_{1}}+u_{x}
$$

where the first term on the right-hand side denotes the rate of water permeation and the second term denotes the rate of freezing on the water permeation front. Then, the density change in the water permeation layer due to refreezing is represented as follows :

$$
x_{\mathrm{i}} \frac{d \rho_{p}}{d \theta}=-\frac{\lambda_{p}}{L}\left(\frac{\partial T_{p}}{\partial x}\right)_{x=x_{\mathrm{i}}}
$$

Table 1 shows the boundary conditions for each period in melting pattern $\mathrm{C}$. The boundary conditions in the other patterns are included in these conditions.

The governing nonlinear differential equations are solved by the Crank-Nicolson finite difference method, using the variable space network method for moving boundary conditions [ 7$]$. In the calculations, the state for the water content ratio $S=0.95$ is regard ed as the saturated state, based on the measurement of the water content at the bottom part of the water permeation layer when the drainage occurs, and also the value of the limiting water content, $S_{c}$, assumed to be 0.1 , referring to the study of Kubota et al.[5]

\section{Experimental Apparatus and Procedure}

Figure 4 shows a schematic diagram of the experimental apparatus. The test container $(50 \mathrm{~mm}$ long, 50 $\mathrm{mm}$ wide and $180 \mathrm{~mm}$ high) in which the test sample is placed is made of acrylic resin and is equipped with a heater at the bottom, which is composed of a sheet of copper, bakelite plates and main and auxiliary heaters to supply a constant heat flux. There is a slit at the bottom of the container to allow for drainage. 
This container is insulated on the sides to reduce heat loss. Part of the insulation is removable to allow for photographic observation.

In order to maintain a constant cold temperature and heat transfer coefficient, a cooling heat exchanger has been installed at the upper part of the container, in which ethylene glycol water solution cooled by a refrigerator circulates. The heat-transfer coefficient in the water solution was obtained from calculating the energy balance in the heat exchanger through the preliminary experiments using snow at $0^{\circ} \mathrm{C}$. Compacted snow and granulated snow were used as the samples. They were packed uniformly to a constant density of $550 \mathrm{~kg} / \mathrm{m}^{3}$. The change in the thickness of each layer was recorded photographically from the side. The water permeation was easily observed using erosin dye added to the bottom of the sample before the experiment was started; however, it was difficult to clearly distinguish between the water permeation layer and the ice layer. The rate of water drainage was obtained by weighing the quantity of drainage at a certain interval.

In a comparison of the predictions with the experimental results, the average snow grain size used as a sample must be known so as to calculate the water permeation rate. In the present paper, the grain is regarded as a sphere and its diameter is determined by using parameters obtained from data of the steady water rise experiments. The diameters obtained were 0.1 and $0.6 \mathrm{~mm}$ for compacted snow and granulated snow respectively.

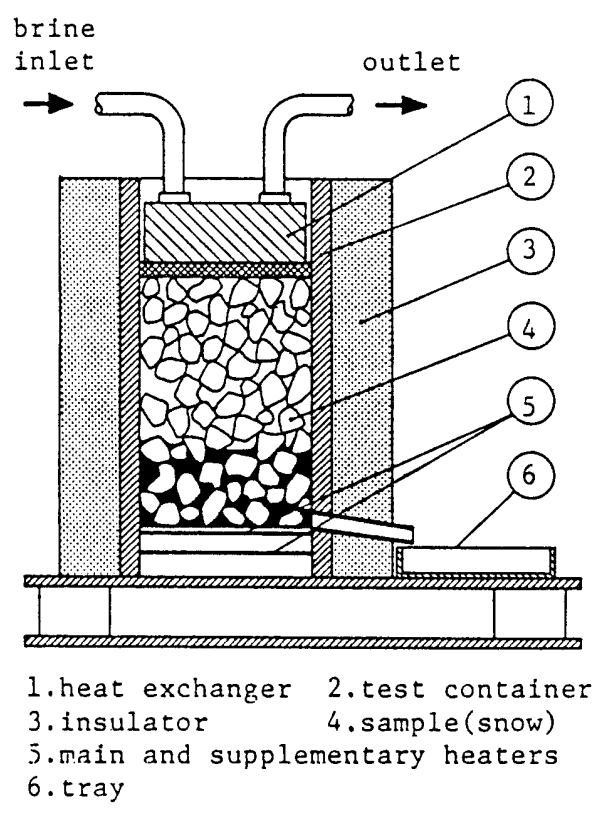

Fig. 4 Experimental apparatus

\section{Results and Discussion}

\section{1 Effects of heat flux on snow layer thickness and water drainage}

We compared the predictions of the data obtained from the melting of snow for various melting conditions. Figure 5 shows the changes in the sample and the rate of water drainage with the time for different heat fluxes in melting pattern $A$. The thickness of the snow layer decreases linearly with time due to the constant supplied heat flux. The thickness of the water permeation layer shown rapidly increases in period ( I ), but it becomes constant in period (II) because of the balancing of its increase due to water permeation with its decrease due to melting. After period (II), it decreases linearly with decreases in the body thickness. Water drainage starts to occur in period (II). The rate of drainage is obtained by subtracting the rate of water permeation from the rate of the resulting water by melting which consists of the melted water and the water content already held in the melted layer. The rate of drainage is nearly constant in period (II), but it increases with time in period (III) because of the decrease in the rate of water permeating away from the melting surface. A larger supplied heat flux results in a shorter melting time and also in a shorter time required for each period. The predictions are in agreement with the experimental data.

Figure 6 shows the comparison between both cases with and without heat loss from the top of the body during the melting process. In pattern $\mathrm{A}$ where heat loss does not occur, the thickness of the water permeation layer remains constant during period (II), as described above. On the other hand, in pattern $B$

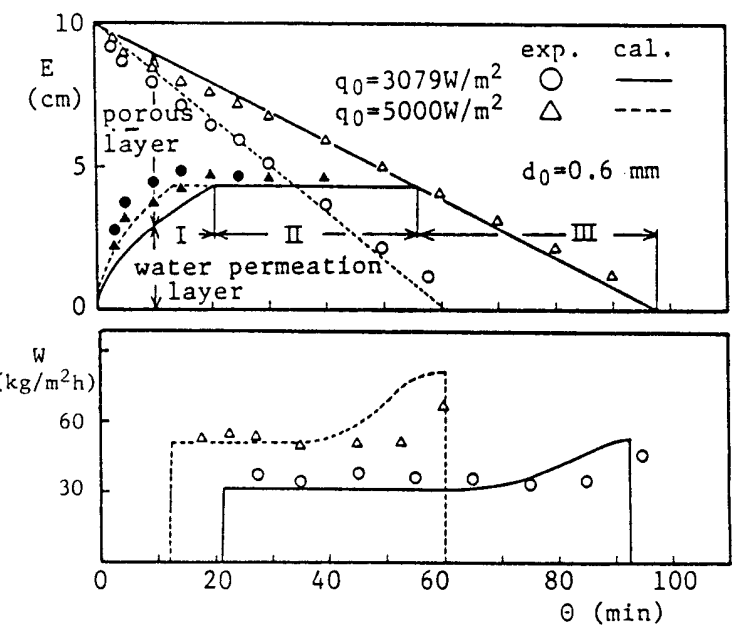

Fig. 5 Comparison between the predicted and actual changes in each layer and the water drainage rate for different heat fluxes (pattern A) 
where heat loss occurs and the formation of an ice lens occurs at the top surface, its thickness decreases gradually with time even in period (II) because the refreezing of permeating water induces the increase in the resistance against water permeation. The rate of water drainage has a lower value in period (IV) in comparison with that in period (III) because only the water resulting from the melting of the ice layer corresponds to the drainage.

Next, in order to indicate the effect of the ability of water to permeate by capillary action on the melting process, the comparison between different snow diameters is shown in Fig. 7. In spite of the same melting conditions, the melting pattern varies with the structure of the snow. Namely, for compacted snow which has a smaller diameter, melting pattern B occurs, and for granulated snow which has a larger diameter, pattern $\mathrm{C}$ occurs because of the lower ability of water to permeate. The melting process in pattern $\mathrm{C}$ is a characteristic one. The water permeation layer increases during period ( $\mathrm{I}$ ), reduces during periods (II) and (III), and disappears at the end of period (III). Following the melting of the ice layer in period (IV), the remaining porous layer starts to melt, so that the water permeation layer increases during period $(\mathrm{V})$ again and reduces during periods (VI) and (VII). Corresponding to this change, the draining of water which starts in period (II) stops during period $(\mathrm{V})$ and $(\mathrm{VI})$ because all the melted water permeates into the water permeation layer. Also, the density of
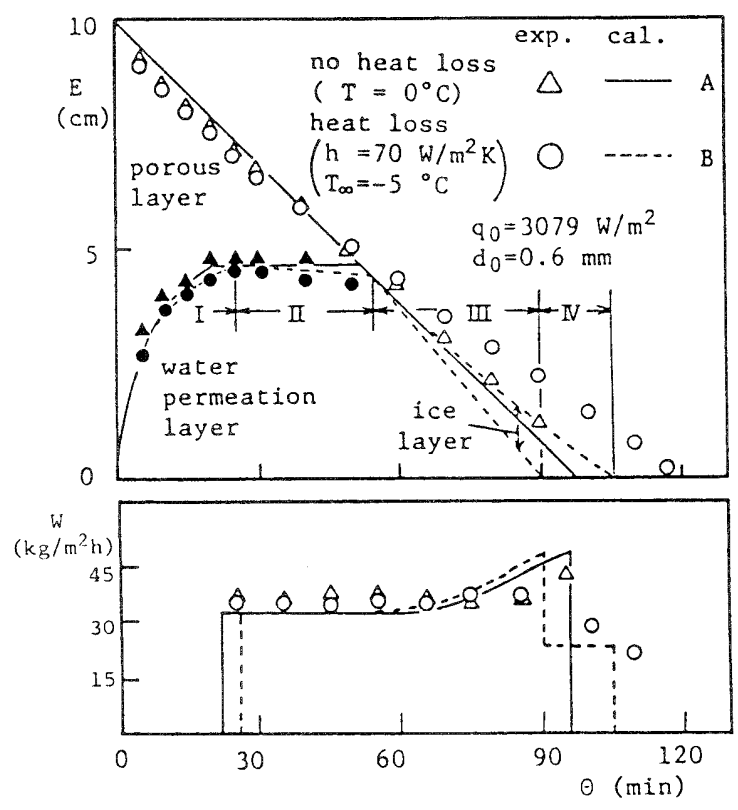

Fig. 6 Comparison between the predicted and actual changes in each layer and the water drainage rate between melting patterns $\mathrm{A}$ and $\mathrm{B}$ the water permeation layer increases with time in periods ( I ), (II) and (V) when the water permeation layer extends into the porous layer, and becomes constant in periods (III) and(VI) when the ice lens is formed.

\subsection{Heat loss and melting efficiency}

As mentioned above, in spite of the same snow density and surrounding conditions, melting patterns vary with the snow structure. Further, it should be noted that the different melting patterns affect the melting time and the melting efficiency. This is because the quantity of heat loss depends on the water permeation and its refreezing under the constant heattransfer coefficient. Figure 8 shows the change in heat loss with time which corresponds to the change in the sample shown in Fig. 7. The heat loss is characteristic of the melting pattern. In pattern $B$, the meltwater rapidly permeates into the body, so that the heat loss increases with time and takes a maximum value when the water permeation front reaches the top surface. It then decreases with the growth of the ice layer and increases with the melting of the ice layer. In pattern $\mathrm{C}$, on the other hand, water permeation is poor and the remaining porous layer acts as an insulator, so that

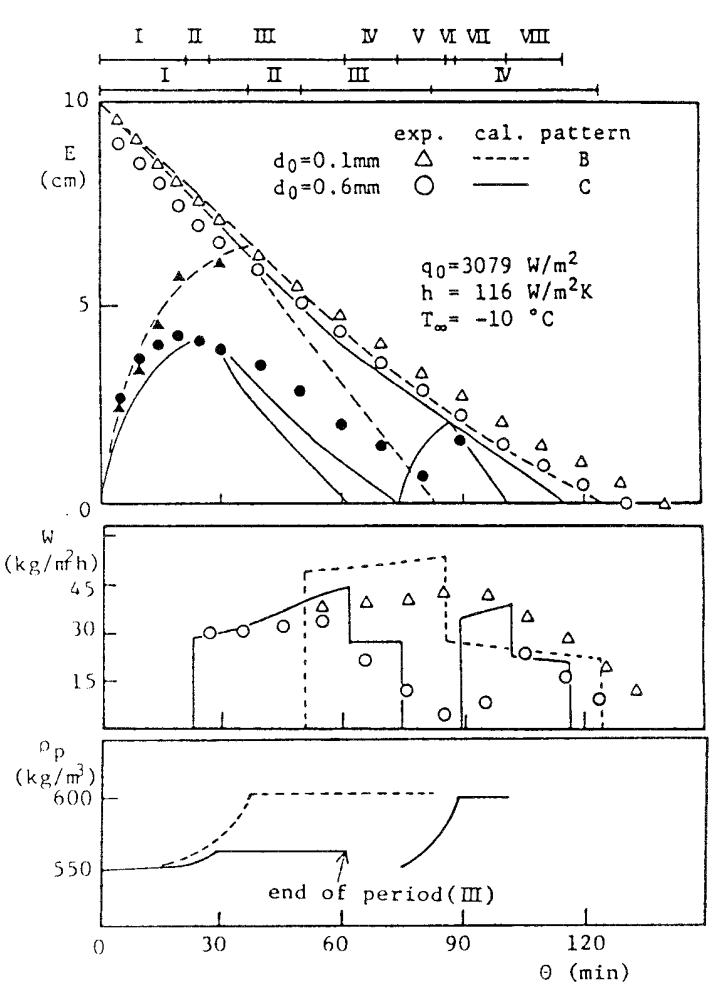

Fig. 7 Comparison between the predicted and actual changes in each layer, the water drainage rate and the density of the water permeation layer for different snow particle diameters (pattern B and C) 


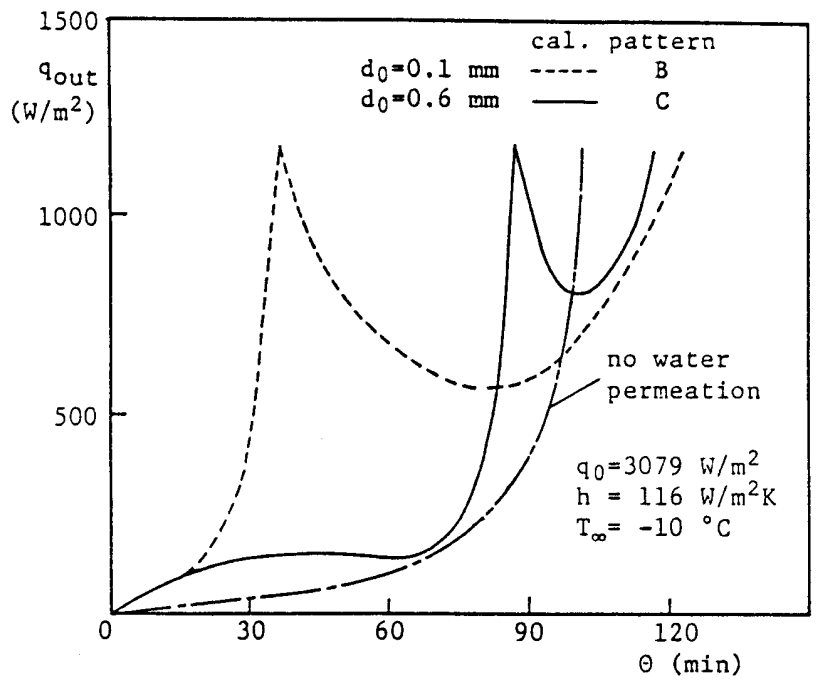

Fig. 8 Comparison of the changes in heat loss between melting patterns $\mathrm{B}$ and $\mathrm{C}$

the rapid increase in heat loss does not appear until the remaining porous layer starts to melt. The total heat loss in pattern $\mathrm{C}$ becomes less than that in pattern B. Accordingly, in spite of the same quantity of snow, the melting in pattern $\mathrm{C}$ occurs in a shorter period of time as compared with that in pattern $\mathrm{B}$. Also, the results calculated assuming the classical Stefan problem by neglecting water permeation are included in this figure as a dash-dot line; they show that the heat loss increases monotonically with time due to melting. From the comparison between the present predictions and the classical Stefan analysis, it is found that water permeation into porous materials results in an increase in heat loss.

Figure 9 shows the change of melting efficiency against supplied heat flux. Melting efficiency is defined as the ratio of the latent heat of the snow layer to the heat actually needed during melting. The efficiency is unity in pattern $\mathrm{A}$, where heat loss does not exist. When heat loss exists, the efficiency becomes lower with a higher supplied heat flux and a smaller snow diameter. The data agree with the present predictions, and the Stefan solution shown by the dash-dot line predicts a higher melting efficiency.

\section{Conclusion}

The melting process of a snow layer has been investigated for the case where heat is supplied from the bottom and where meltwater also drains from the bottom side. The melting was divided into three patterns, considering the existence of an ice lens formed by the refreezing of the permeating water. The melt. ing pattern depends on the snow thickness, the diame-

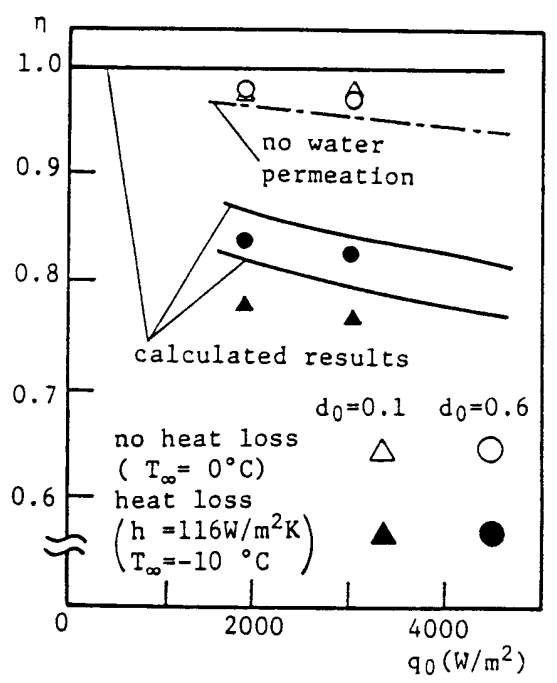

Fig. 9 Comparison between the predicted and actual melting efficiency

ter of the snow particles, the supplied heat flux and the quantity of heat loss.

A one-dimensional melting model including water drainage was formulated, accounting for water permeation and its refreezing in a snow layer. The calculated results for the time change of each layer and the rate of water drainage are in agreement with the experimental results for all melting patterns.

The heat loss from the top of the body varies with melting patterns under the condition of a constant heat-transfer coefficient. It is found that the melting time and the melting efficiency are affected by water permeation and its refreezing, and the results calculated assuming the classical Stefan problem by neglecting water permeation predict a higher melting efficiency.

\section{References}

(1) Aoki, K., Hattori, M., Chiba, S. and Hayashi, Y., ASME paper 81-WA/HT (1981).

(2) Aoki, K., Hattori, M. and Chiba, S., Bull. JSME, Vol. 29, No. 253 (1986), p. 2138.

(3) Taylor, G. S. and Luthin, J. N., Canadian Geotechnical J., Vol. 15 (1978), p. 548.

(4) Ohtani, S. and Maeda, S., Kagaku Kogaku, (in Japanese), Vol. 28, No. 5 (1964), p. 362.

(5) Kubota, N., Kawakami, T. and Ohtani, S., Kagaku Kogaku, (in Japanese), Vol. 32, No. 8 (1968), p. 822.

(6) Seki, N., Fukusako, S. and Tanaka, M., Trans. Jpn. Soc. Mech. Eng., (in Japanese), Vol. 43 (1977), p. 1086.

(7) Murray, W. D. and Landis, F., Trans. ASME Ser. C, Vol. 81, No. 2 (1959), p. 421. 